\title{
Correction to: Application of combined kernel function artificial intelligence algorithm in mobile communication network security authentication mechanism
}

\section{Zhongru Wang $^{1,2} \cdot$ Binxing Fang $^{1}$}

Published online: 15 July 2019

○) Springer Science+Business Media, LLC, part of Springer Nature 2019

\section{Correction to: The Journal of Supercomputing https://doi.org/10.1007/s11227-019-02896-5}

The spelling of Binxing Fang's given name was incorrect. The original article has been corrected.

Publisher's Note Springer Nature remains neutral with regard to jurisdictional claims in published maps and institutional affiliations.

The original article can be found online at https://doi.org/10.1007/s11227-019-02896-5.

Zhongru Wang

wangzhongru@bupt.edu.cn

1 Key Laboratory of Trustworthy Distributed Computing and Service (BUPT), Ministry of Education, Beijing University of Posts and Telecommunications, Beijing, China

2 Zhejiang Lab, Hangzhou, China 